\title{
LUIS BRIONES MORALES, SU APORTE A LOS ESTUDIOS Y DIFUSIÓN DEL ARTE COLONIAL EN EL NORTE DE CHILE: UN RELATO
}

\author{
Juan Manuel Chacama ${ }^{1}$
}

Luis Eduardo Briones Morales, profesor de Estado en Artes Plásticas, profesó siempre un cariño e interés por las manifestaciones del llamado arte rupestre, especialmente por los geoglifos. Su trabajo de investigación, difusión y preservación de este arte ha sido ampliamente conocido en nuestro territorio nacional y fuera de él también; mucho menos conocido es el aporte que el profesor Briones realizó en torno al arte colonial presente en las numerosas iglesias y capillas del norte de Chile.

El año 1979 recibe una beca de la Organización de Estados Americanos, que le permite participar en el V Curso de Conservación y Restauración de Bienes Muebles, realizado por el Instituto Nacional de Cultura en Cusco, Perú. En dicho curso de seis meses de duración, tiene la oportunidad de acercarse a la riqueza del arte y la arquitectura colonial presente en las imponentes iglesias del Cusco y sus alrededores. De la mano de los reconocidos profesores Teresa Gisbert y José de Mesa, recorre y aprende sobre distintos estilos arquitectónicos, sobre retablos, pinturas de caballete y murales que ornamentan los templos de la zona cusqueña. Allí surge la necesidad de saber qué pasó en nuestro norte de Chile, las pequeñas iglesias y capillas de la precordillera y altiplano contaron con manifestaciones similares.

De regreso a la ciudad de Arica, donde impartía la cátedra de Historia del Arte Iberoamericano en la sede Arica de la Universidad de Chile, Luis recorrió lugares, iglesias y capillas en la precordillera y altiplano de la región, documentando y estudiando un nuevo mundo de arte colonial que se abría ante sus ojos. En el año 1983 y siguiendo la huella de destacados arquitectos nacionales (Benavides 1941; Benavides et al. 1977; Montandon 1967 entre otros), Luis Briones junto al profesor Pedro Villaseca entregan su primer gran aporte al conocimiento de este tema casi desconocido para la época: "Pintura Religiosa en Tarapacá. Fe y color en el desierto" (Villaseca y Briones 1983).

En 1982, año de fundación de la Universidad de Tarapacá, Luis se incorpora a esta a través de su Departamento de Antropología y Museo Arqueológico San Miguel de Azapa. Desde dicho espacio académico continuó con su temática de mayor interés. Paralelamente, el estudio de los geoglifos del norte de Chile y fuertemente apoyado por jóvenes profesionales del Museo de Azapa, siguió incursionando en temáticas del arte colonial. Durante el año 1984 interviene en el rescate de las pinturas murales de la iglesia de Huasquiña, localidad ubicada al interior de la ciudad de Iquique. Es quizás esta acción patrimonial la que marca en él un punto de inflexión en los estudios y difusión del arte colonial en el norte de Chile.

Un hito relevante en su vida fue el acercamiento con la Organización de Estados Americanos (OEA), sede Chile, lo que le permitió obtener un proyecto que, con el nombre de "Estudio y restauración del patrimonio cultural en el área andina del norte de Chile (1986-87)", produjo un acercamiento a los sitios arqueológicos de la precordillera de Arica y al templo de Parinacota. De este modo, sitios conocidos con el nombre de Pukaras fueron sistemáticamente relevados mediante sendos levantamientos topográficos, generándose por primera vez una visión global de estos monumentos. Zapahuira, Incaullo, Huaihuarani, Lupica, Saxamar, Inacauta, Vila 1 y 2, Molle Grande, entre varios otros, dejaron de ser sitios "de oídas" y tuvieron su referente georreferenciado y planimétrico, convirtiéndose en base fundamental para sucesivas investigaciones y publicaciones en torno a la prehistoria tardía de la precordillera de Arica.

Dos acciones relevantes tuvo el proyecto; una consistió en la puesta en valor del sitio conocido como Tambo Zapahuira I ubicado a la altura del km 76 de la ruta internacional $11 \mathrm{CH}$. El sitio, ampliamente

1 Departamento de Antropología, Universidad de Tarapacá, Arica, Chile. jchacama@uta.cl, juanchacama@gmail.com 
referenciado en la literatura arqueológica pero nunca antes excavado, fue puesto en valor e identificado como un depósito estatal "collca", representativo de la presencia del Incario en el norte de Chile (Muñoz et al. 1997). El sitio fue en gran medida sometido a limpieza, despeje de muros, excavado estratigráficamente, datado y reconstruido, pasando de ser un lugar mencionado por la literatura a un atractivo turístico informado. Las acciones emprendidas en torno a Zapahuira I motivaron en su momento que la Corporación Nacional de Desarrollo Indígena (CONADI) y la Dirección de Vialidad ejecutaran un proyecto que modificó el eje de la ruta $11 \mathrm{CH}$, produciendo un by pass en torno a este Monumento Nacional.

La otra acción relevante del proyecto fue la protección de las pinturas murales del interior de la iglesia de Parinacota, cuyo edificio y murales datan del siglo XVIII, periodo Colonial Tardío. La techumbre del templo se asentaba directamente sobre los muros de la iglesia, por tanto en épocas de lluvia el agua escurría y se depositaba directamente sobre los muros filtrándose en ellos y, por ende, afectando los murales pintados en su interior, los cuales representan imágenes de santos y escenas de la pasión de Jesús, así como un gran recuadro sobre el Juicio Final.

La forma como se procedió a su protección fue prolongar la techumbre fuera de los paramentos de la iglesia, evitando de esta manera que la humedad penetrara los muros, acción implicó destechar la iglesia. Se realizaron, junto a comuneros de Parinacota, rogativas y una vilancha antes de comenzar las acciones de reparación de la techumbre pero, una nevada de grandes proporciones afectó la localidad con la consabida muerte de crías del ganado local; luego, el gran movimiento sísmico de 1987, que afectó toda la región de Arica incluyendo la localidad de Parinacota, provocó la caída y fractura, desde su posición en el altar, de la imagen de la Virgen de la Natividad, Patrona de Parinacota. En la misma época también fallece la fabriquera de la iglesia. Tales acontecimientos catastróficos fueron considerados por parte de la comunidad como consecuencia de destechar de la iglesia. Luis Briones,en tanto cara visible del proyecto, recibió estoicamente aunque con pesadumbre esa carga que de alguna manera lo acompañó siempre.

La OEA, por su parte, recibió de buena manera los informes finales del proyecto: "Se pueden hacer buenas cosas con poco dinero", señalaron en su momento y estuvieron dispuestos a apoyar un segundo proyecto; esta vez trasnacional. A la Universidad de Tarapacá, con Luis Briones como coordinador, la acompañaron la Universidad San Antonio Abad del Cusco, a través del antropólogo Jorge Flores Ochoa y el Instituto Boliviano de Cultura, representado por la arquitecta Teresa Gisbert. El proyecto en cuestión se tituló "Catastro, evaluación y estudio de la Pintura Mural en el área Centro Sur Andina" (Proyecto trinacional: Chile, Bolivia, Perú, años 1988 - 89), y fue elaborado en sucesivas visitas y reuniones conjuntas entre los tres países involucrados en las ciudades de Cusco, La Paz y Arica.

En el caso de Chile, el objetivo central del proyecto fue un estudio sistemático de 77 templos comprendidos en toda la franja de sierra y puna de las actuales regiones I de Tarapacá y XV de Arica y Parinacota, cuyas edificaciones abarcan un periodo comprendido entre el siglo XVII y la primera mitad del XX. Para realizar el estudio señalado, se emprendió una labor que partía desde la recopilación de antecedentes en terreno: confección de planos, documentación fotográfica, conversaciones con las comunidades, anotaciones de inscripciones en los edificios, revisión de libros de fábrica, etc. Tal trabajo demandó visitar una gran cantidad de comunidades, algunas de ellas sin acceso vehicular, de manera que se pudiera abarcar el mayor número de templos posibles.

La tarea emprendida comprendió largas temporadas de campo, salidas de siete días continuos con toda la logística necesaria para permanecer en terreno; en ocasiones, sin posibilidades de reponer alimentos, por ejemplo. Pero no todo fue girar en torno a las temáticas del proyecto; armar y desarmar campamentos, tertulias a la luz de un fogón y por supuesto la preparación de alimentos, siempre acompañada de algunos mostos, fueron la parte lúdica, amable y amigable del proyecto que, en gran medida, refleja el alma de Luis: un fogón a leña, ollas tiznadas y una conversación de los trabajos realizados en el día; luego un reparador descanso en nuestras respectivas carpas y, al día siguiente, proseguir nuestro viaje hacia un nuevo destino y un nuevo templo que documentar.

Los resultados de este largo y enriquecedor trabajo quedaron expresados en un informe de dos volúmenes que contienen descripciones iconográficas, planos de los programas murales y el estado de conservación de estos. Se pudieron identificar y documentar 15 templos que aún conservaban vestigios de pintura mural, algunos de ellos muy deteriorados y otros ya desaparecidos. Por lo anterior, el material documental rescatado, en algunos casos, es quizás el último vestigio de un arte que va desapareciendo lentamente, ya sea por abandono, 


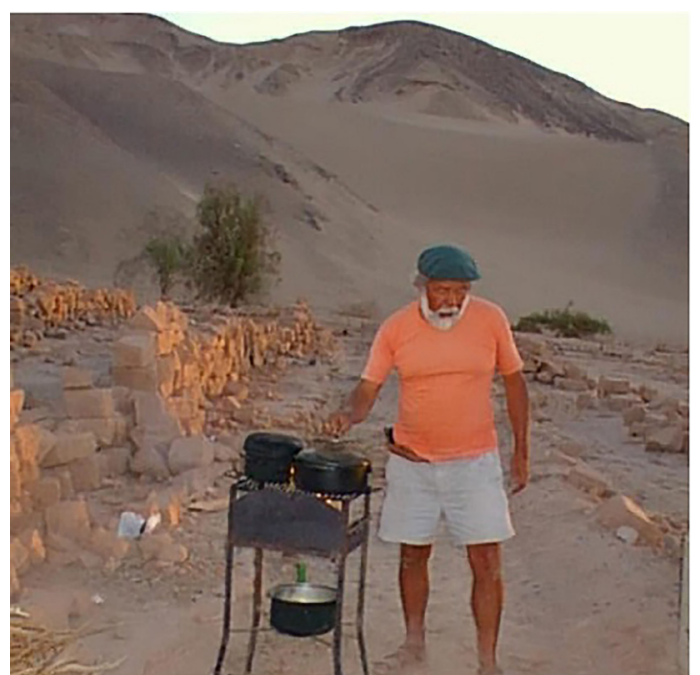

Chacras en Quebrada Maní, Guatacondo.

por razones climáticas u otras. En lo práctico y en lo que respecta al proyecto, se identificaron al menos tres momentos estilísticos: Barroco, Neoclásico y
Pintura popular, asociados a los siglos XVIII, XIX y primera mitad del XX, respectivamente. Estos tres momentos fueron caracterizados desde el estilo pictórico y contextualizados según el momento histórico en que fueron producidos.

Con el tiempo, nuevas contribuciones al tema se fueron sumando y enriqueciendo el panorama obtenido desde el trabajo de campo (Briones y Chacama 1992; Chacama 2009, 2010; Chacama y Briones 1992, 1997; Chacama et al. 1988; Espinosa y Chacama 2005). Así, el aporte seminal de Luis Briones fue dando sus frutos. Y lo que en un inicio fuera una historia desconocida se convirtió en una fuente documental de primer orden para comprender los procesos culturales acaecidos en los Altos de Arica y Tarapacá partir de la llegada hispana y la evangelización de los territorios del norte de Chile. Mirado desde ese punto de vista, el aporte de Luis Briones a los estudios y difusión del arte colonial en el norte de Chile fue fundamental, pues abrió un nuevo campo de estudios con nuevas fuentes documentales: las imágenes pictóricas y su rescate patrimonial. Gracias Luis.

\section{Referencias Citadas}

Benavides, A. 1941. La Arquitectura en el Virreinato del Perú y en la Capitanía General de Chile. Ediciones Ercilla, Santiago.

Benavides, J., R. Márquez de la Plata y L. Rodríguez 1977. Arquitectura del Altiplano: Caserío y Villorrios Ariqueños. Facultad de Arquitectura y Urbanismo, Universidad de Chile, Santiago.

Briones, L. y J. Chacama 1992. Patrimonio cultural del norte grande de Chile en el momento del contacto. Siglos XIV, XV y XVI. Revista Campus Iquique III (20):58-50.

Chacama, J. 2009. Imágenes y palabras, dos textos para un discurso: La prédica pastoral en los Andes coloniales. Doctrina de Codpa (Altos de Arica), siglo XVIII. Diálogo Andino 33:7-27.

Chacama, J. 2010. Evangelización en el Norte de Chile. Una mirada desde textos escritos y pictóricos. Actas XVII Congreso Nacional de Arqueología Chilena Chilena, Valdivia 2006, Tomo 2, pp. 967-978.

Chacama, J. y L. Briones 1992. Iglesia española - Templo andino. Revista Campus Iquique III (20):101-106.

Chacama J. y L. Briones 1997. Arte Andino reflejo de una cultura. En El Altiplano. Ciencia y Conciencia en los Andes. II
Simposio Internacional de Estudios Altiplánicos, pp. 297-299. Universidad de Chile, Arica.

Chacama, J., L. Briones y G. Espinosa 1988. El arte mural en las iglesias coloniales en la primera región y la tradición pictórica andina en el extremo norte de Chile. Diálogo Andino 7:101-120.

Espinosa, G. y J. Chacama 2005. Pintura mural del siglo XX en el norte de Chile: Modernidad y tradición en Tarapacá en un contexto de "chilenización". Actas VI Congreso Internacional de Etnohistoria: Buenos Aires (versión digital). Editado por Universidad de Buenos Aires, Buenos Aires.

Montandon, R. 1967. El Barroco en la Sierra de Tarapacá. Anales de la Universidad de Chile 141-144:74-80.

Muñoz, I., J. Chacama, G. Espinosa y L. Briones 1997. La ocupación prehispánica tardía en Zapahuira y su vinculación a la organización económica y social Inca. Chungara Revista de Antropología Chilena 18:67-89.

Villaseca, P. y L. Briones 1983. Pintura Religiosa en Tarapacá. Fe y color en el Desierto. Editora Cabo de Hornos, Santiago. 
